\title{
Disponibilidade aparente do fósforo em alimentos vegetais e suplementação da enzima fitase para tilápia-do-nilo ${ }^{1}$
}

\author{
Giovani Sampaio Gonçalves², Luiz Edivaldo Pezzato ${ }^{3}$, Pedro de Magalhães Padilha ${ }^{4}$, \\ Margarida Maria Barros ${ }^{3}$
}

\footnotetext{
1 Projeto financiado pela Fundação de Amparo à Pesquisa do Estado de São Paulo - Fapesp.

2 Instituto de Pesca - São José do Rio Preto/São Paulo - Brasil.

${ }^{3}$ Departamento de Nutrição Animal, FMVZ, Universidade Estadual Paulista, Botucatu/São Paulo.

${ }^{4}$ Departamento de Química e Bioquímica - IB - Universidade Estadual Paulista, Botucatu/São Paulo.
}

RESUMO - Este estudo foi realizado com o objetivo de avaliar o efeito da fitase (0, 1.000 e $2.000 \mathrm{uf} / \mathrm{kg})$ na disponibilidade aparente de P de cinco alimentos energéticos (milho, milho extrusado, farelo de trigo, farelo de arroz e sorgo baixo tanino) e cinco alimentos protéicos (soja extrusada, farelo de soja, farelo de girassol, farelo de algodão e glúten de milho) utilizandose uma ração purificada como controle. Foram utilizados 100 juvenis $(100,00 \pm 5,00$ g) de tilápia-do-nilo (Oreochromis niloticus) alojados em dez gaiolas para manejo de alimentação e coleta de fezes. Para cada alimento e cada nível de fitase avaliado, foram coletadas amostras em cinco gaiolas, totalizando cinco repetições por tratamento. Os resultados obtidos indicaram que a suplementação de até $2.000 \mathrm{uf} / \mathrm{kg}$ de fitase não aumentou a disponibilidade aparente de $\mathrm{P}$ do farelo de trigo e do farelo de algodão. Entretanto, o nível de $1.000 \mathrm{uf} / \mathrm{kg}$ aumentou a disponibilidade aparente de P da soja extrusada e do farelo de girassol, enquanto o nível de $2.000 \mathrm{uf} / \mathrm{kg}$ proporcionou essa resposta para o farelo de milho, o milho extrusado, o sorgo baixo tanino, o farelo de arroz, o farelo de soja e o glúten de milho.

Palavras-chave: fitase, fósforo, minerais, nutrição, tilápia

\section{Apparent phosphorus availability in vegetable feedstuffs and supplementation of phytase enzyme for Nile tilapia Oreochromis niloticus}

\begin{abstract}
This study was carried out to evaluate effects of phytase $(0,1,000$, and 2,000 uf $/ \mathrm{kg})$ on apparent P availability of five energetic feeds (corn, extruded corn, wheat meal, rice meal and low-tannin sorghum) and five protein feeds (extruded soy, soybean meal, sunflower meal, cottonseed meal and corn gluten) using a purified diet as control. One hundred $(100.00 \pm 5.00 \mathrm{~g})$ Nile tilapia juveniles (Oreochromis niloticus) were allotted to ten cages to allow feeding and fecal collection. For each feed and each phytase level evaluated samples were collected from five cages, in a total of five replications per treatment. The obtained results showed that the phytase supplementation up to $2,000 \mathrm{uf} / \mathrm{kg}$ did not increase apparent $P$ availability present in wheat meal or cottonseed meal. However, the level of 1,000 uf/kg increased the apparent P availability present in extruded soy and sunflower meal, while the level of 2,000 uf/kg promoted this response for corn meal, extruded corn, low-tannin sorghum, rice meal, soybean meal and corn gluten.
\end{abstract}

Key Words: mineral, nutrition, Oreochromis niloticus, phosphorus, phytase, tilapia

\section{Introdução}

A criação intensiva de peixes exige a utilização de rações completas, uma vez que nesses sistemas o alimento oferecido é a única fonte de alimentação e o alimento natural tem muito pouca participação no crescimento dos peixes. Atualmente, nutricionistas e fabricantes de rações estão bem atentos à importância de rações balanceadas e ecologicamente corretas, com quantidade de nutrientes que não exceda as exigências das espécies. Alguns fatores devem ser considerados para minimizar o efeito poluidor dos efluentes produzidos pelas pisciculturas, entre eles, a formulação das rações utilizadas, ou seja, a escolha dos alimentos, a concentração de fósforo e a disponibilidade desse mineral. Uma vez que o fósforo (P) é um elemento essencial em rações para peixes (NRC, 1993), sua concentração na dieta deve atender às exigências necessárias para o bom desempenho sem, contudo, comprometer a qualidade da água de cultivo, pois é um dos nutrientes limitantes que mais eutrofizam da água, sendo considerado por vários órgãos fiscalizadores como elementos com alta capacidade poluidora. 
A descarga de nutrientes em efluentes de piscicultura está direta ou indiretamente associada à alimentação, ou seja, alimentos não digestíveis, fósforo da dieta na forma não disponível e excesso de alimento são as principais formas de contribuição para o aumento dos nutrientes no efluente. Para formulações corretas de rações, indiferentemente do nutriente em questão, não necessárias inicialmente duas importantes informações: a exigência nutricional da espécie e a disponibilidade dos nutrientes em cada alimento a ser utilizado na ração (Riche \& Brown 1996). De acordo com o NRC (1993), a exigência de fósforo total para tilápia-do-nilo (Oreochromis niloticus) é 0,5\%. Entretanto, existem poucos valores de disponibilidade aparente do fósforo em alimentos de origem vegetal utilizados em rações práticas para tilápia-do-nilo.

O uso de alimentos protéicos e energéticos de origem vegetal merece grande destaque, principalmente em países de clima tropical e subtropical, onde são produzidos em grande escala, apresentam menor custo e estão disponíveis durante a maior parte do ano. No entanto, alimentos de origem vegetal apresentam baixos níveis de fósforo e baixa disponibilidade desse mineral (Furuya et al., 2001). Podem conter de 0,5 a 6,0\% de ácido fítico e de 50 a $90 \%$ de seu total de fósforo na forma de fitato (Nolan \& Duffin 1987). O fitato é capaz de se complexar com cátions, proteínas, lipídeos e amido, tornando grande parte destes nutrientes não digestível para os peixes, em razão da ausência da enzima fitase endógena (Vielma et al. 1998), que promove a hidrólise da ligação éster entre o fosfato e a molécula de inositol. Vários trabalhos com as mais diversas espécies de peixes foram realizados com sucesso objetivando avaliar a suplementação da enzima fitase em rações à base de alimentos vegetais, entre eles, destacam-se as pesquisas realizadas por Andrews et al. (1973), Ketola (1975), Ogino et al. (1979), Rodehutscord \& Pfeffer (1995), Schãfer et al. (1995), OlivaTeles et al. (1998), Vielma et al. (1998), Foster et al. (1999), Furuya et al. (2001) e Gonçalves et al. (2005).

No entanto, o conhecimento da ação desta enzima em disponibilizar os minerais presentes em cada alimento não foi avaliado. Uma vez que os alimentos que compõem as rações e as proporções utilizadas variam conforme a espécie, o hábito alimentar, a fase de crescimento, o custo da matériaprima, a disponibilidade e a forma de processamento, objetivou-se com este trabalho avaliar a disponibilidade do fósforo de alimentos de origem vegetal e a ação da suplementação da fitase em dietas para tilápia-do-nilo.

\section{Material e Métodos}

O estudo foi realizado na Unesp - Universidade Estadual Paulista, Faculdade de Medicina Veterinária e Zootecnia, Departamento de Melhoramento e Nutrição, Laboratório de Nutrição de Organismos Aquáticos - Aquanutri, unidade integrada ao Centro de Aqüicultura da Unesp. Foram avaliados dez alimentos de origem vegetal, cinco protéicos (farelo de soja, soja extrusada, farelo de girassol, farelo de algodão e glúten de milho) e cinco energéticos (milho, milho extrusado, sorgo baixo tanino, farelo de arroz e farelo de trigo) (Tabela 1).

Para determinação dos coeficientes de digestibilidade aparente (CDA), foi elaborada uma ração-referência purificada (AIN, 1977), com base na proteína da albumina e

Tabela 1 - Composição química mineral dos alimentos utilizados nas rações experimentais (\% MS) ${ }^{1}$

Table 1 - Mineral chemical composition of the feeds used in the experimental diets (\% DM) ${ }^{1}$

\begin{tabular}{|c|c|c|c|c|c|c|c|}
\hline $\begin{array}{l}\text { Alimento } \\
\text { Feed }\end{array}$ & $\mathrm{P} 2$ & $\mathrm{Ca}^{2}$ & $\mathrm{Mg}^{3}$ & $\mathrm{Mn}^{3}$ & $\mathrm{Cu}^{3}$ & $\mathrm{Zn}^{3}$ & $\mathrm{Fe}^{3}$ \\
\hline \multicolumn{8}{|l|}{ Energético (Energetic) } \\
\hline Milho (Corn) & 0,10 & 0,20 & 0,07 & 29,40 & 3,85 & 37,52 & 116,66 \\
\hline Milho extrusado (Extruded corn) & 0,10 & 0,19 & 0,08 & 5,00 & 2,68 & 21,92 & 17,79 \\
\hline Farelo de trigo (Wheat meal) & 0,74 & 0,55 & 0,52 & 116,54 & 16,25 & 132,43 & 215,29 \\
\hline Sorgo baixo tanino (Low-tannin sorghum) & 0,17 & 0,20 & 0,18 & 31,42 & 5,27 & 39,15 & 99,46 \\
\hline Farelo de arroz (Rice meal) & 1,78 & 0,30 & 0,96 & 67,31 & 12,28 & 99,73 & 71,67 \\
\hline \multicolumn{8}{|l|}{ Protéico (Protein) } \\
\hline Farelo de soja (Soybean meal) & 0,40 & 1,07 & 0,37 & 55,83 & 21,36 & 73,03 & 62,82 \\
\hline Farelo de soja extrusado (Extruded soybean meal) & 0,58 & 0,54 & 0,36 & 54,98 & 13,74 & 61,18 & 54,07 \\
\hline Glúten de milho (Corn gluten) & 0,40 & 0,87 & 0,13 & 16,42 & 20,05 & 75,48 & 61,30 \\
\hline Farelo de algodão (Cottonseed meal) & 0,72 & 0,51 & 0,52 & 33,89 & 15,18 & 61,18 & 143,87 \\
\hline Farelo de girassol (Sunflower meal) & 0,59 & 1,19 & 0,66 & 63,90 & 6,02 & 123,09 & 177,04 \\
\hline
\end{tabular}


Tabela 2 - Composição percentual das rações

Table 2 - Percentage composition of the diets

\begin{tabular}{|c|c|c|c|c|}
\hline Ingrediente (Ingredient) & $\operatorname{Ref}^{1}$ & $\mathrm{UF}_{1}{ }^{2}$ & $\mathrm{UF}_{2}{ }^{3}$ & $\mathrm{UF}_{3}{ }^{4}$ \\
\hline Albumina (Albumin) & 30,00 & 12,00 & 12,00 & 12,00 \\
\hline Dextrose (Dextrin) & 25,00 & 10,00 & 10,00 & 10,00 \\
\hline Amido de milho (Corn starch) & 25,00 & 10,11 & 10,09 & 10,07 \\
\hline Gelatina (Gelatin) & 10,00 & 4,00 & 4,00 & 4,00 \\
\hline Óleo de soja (Soybean oil) & 4,38 & 1,75 & 1,75 & 1,75 \\
\hline$\alpha$-celulose ( $\alpha$-cellulose $)$ & 5,00 & 2,00 & 2,00 & 2,00 \\
\hline Supl.vit. min. ${ }^{5}$ (Suppl. min. vit) & 0,50 & 0,02 & 0,02 & 0,02 \\
\hline $\mathrm{BHT}^{6}$ & 0,02 & 0,02 & 0,02 & 0,02 \\
\hline Óxido de cromo (Chromic oxide) & 0,10 & 0,10 & 0,10 & 0,10 \\
\hline Fitase (Phytase) & - & - & 0,02 & 0,04 \\
\hline
\end{tabular}

Alimento energético (Energetic feed)

Milho (Corn)

Milho extrusado (Extruded corn)

Sorgo baixo tanino (Sorghum low tannin)

Farelo de arroz (Rice meal)

Farelo de trigo (Wheat meal)

Alimento protéico (Protein feed)

Farelo de soja (Soybean meal)

Soja extrusada (Extruded soybean)

Farelo de girassol (Sunflower meal)

Farelo de algodão (Cottonseed meal)

Glúten de milho (Corn gluten meal)

\begin{tabular}{llll}
- & 60,00 & 60,00 & 60,00 \\
- & 60,00 & 60,00 & 60,00 \\
- & 60,00 & 60,00 & 60,00 \\
- & 60,00 & 60,00 & 60,00 \\
- & 60,00 & 60,00 & 60,00 \\
\hline
\end{tabular}

\begin{tabular}{llll}
- & 60,00 & 60,00 & 60,00 \\
- & 60,00 & 60,00 & 60,00 \\
- & 60,00 & 60,00 & 60,00 \\
- & 60,00 & 60,00 & 60,00 \\
- & 60,00 & 60,00 & 60,00 \\
\hline
\end{tabular}

${ }^{1}$ Ref. = ração-referência (reference diet); ${ }^{2}$ uf $1=0$ unidade de fitase $/ \mathrm{kg} ;{ }^{3}$ uf $2=1.000$ unidades de fitase $/ \mathrm{kg} ;{ }^{4}$ uf $3=2.000$ unidades de fitase $/ \mathrm{kg} ;{ }^{5}$ Supl vit. min. (mineral and vitamin mix): níveis de garantia por kg do produto (warranted levels per $\mathrm{kg}$ ): vit. A = $1200.000 \mathrm{Ul}$; vit. D3 = $200.000 \mathrm{UI}$; vit. E = $12000 \mathrm{mg}$; vit. $\mathrm{K} 3=2.400 \mathrm{mg}$; vit. B1 = 4.800mg; vit. B2 $=4.800 \mathrm{mg}$; vit. B6 $=4.000 \mathrm{mg}$; vit. B12 = $4.800 \mathrm{mg}$; ác. fólico (folic acid) $=1.200 \mathrm{mg}$; pantotenato de Ca (Calcium pantothenate $)=12000 \mathrm{mg}$; vitamina $\mathrm{C}($ vitamin $\mathrm{C})=48.000 \mathrm{mg}$; biotina $($ biotin $)=48 \mathrm{mg}$; colina $($ choline $)=65.000 \mathrm{mg} ;$ niacina $($ niacin $)=4.000 \mathrm{mg} ; \mathrm{Fe}=10.000 \mathrm{mg}$ $\mathrm{Cu}=600 \mathrm{mg} ; \mathrm{Mn}=4.000 \mathrm{mg} ; \mathrm{Zn}=6.000 \mathrm{mg} ; \mathrm{I}=20 \mathrm{mg} ; \mathrm{Co}=2 \mathrm{mg}$ e Se $=20 \mathrm{mg} ;{ }^{6}$ BHT = antioxidante (antioxidant) - Butil hibroxi tolueno (Butyl hydroxi toluene).

da gelatina, formulada para conter 32,00\% de proteína digestível (PD) e 3.000 kcal de energia digestível (ED) por kg de ração. A ração-referência foi adicionada dos alimentos a serem avaliados na proporção de 40,00\% (Tabela 2).

Foram confeccionadas 31 rações, dez sem suplementação de fitase, dez com 1.000 uf/kg e dez com 2.000 uf/kg, além da ração-referência (purificada), sem adição de enzima. A ração-referência foi utilizada para determinação do coeficiente de digestibilidade do nutriente.

O produto utilizado para suplementação de fitase (Natuphos ${ }^{\circledR} 5000$, BASF, Germany) apresenta concentração de 5.000 uf/g do produto. Ressalta-se que uma unidade de fitase ativa (uf) é a quantidade de fitase que libera fósforo inorgânico do fitato de sódio (5,1 mM) a uma taxa de $1 \mu \mathrm{mol} /$ min em pH 5,5 e temperatura de $37^{\circ} \mathrm{C}$ (Kornegay, 1999).

Na confecção das rações, após moagem em moinho de faca e obtenção de curva granulométrica, de 0,6 a 0,8 mm, os alimentos foram pesados, homogeneizados em misturador elétrico e acrescidos de água $\left(50,0 \pm 2,0^{\circ} \mathrm{C}\right)$ na proporção de 20,00\% do peso total para obtenção de uma mistura possível de peletização. Quando necessário, a fitase foi acrescida na forma seca juntamente ao alimentoteste. As rações foram peletizadas em equipamento elétrico e desidratadas em estufa de ventilação forçada $\left(50,0 \pm 1,0^{\circ} \mathrm{C}\right)$ durante 24 horas.

Para obtenção das fezes, foram utilizados 100 juvenis de tilapia-do-nilo com 100,0 \pm 5,0 g de peso vivo alimentados separadamente com as rações em estudo. Durante o período de alimentação, os peixes foram alojados em gaiolas de formato circular (80,0 cm de diâmetro e 60,0 cm de altura), confeccionados em tela plástica (malha de 1,5 cm entrenós). Cada gaiola fez parte de um conjunto de aquários circulares (aquários de alimentação), com capacidade para $250 \mathrm{~L}$ de água, em um sistema fechado de circulação com renovação total da água a cada 60 minutos.

O sistema de alimentação (bateria de aquários) era dotado de filtro físico e biológico, com aeração e controle digital para manutenção da temperatura na faixa de conforto para a espécie $\left(26,0 \pm 1,0^{\circ} \mathrm{C}\right)$. Os peixes foram mantidos nestes aquários de alimentação durante o dia, de 8 às $17 \mathrm{~h}$, onde foram alimentados à vontade com maior freqüência no final tarde. As dez gaiolas de alimentação foram divididas em dois grupos (alimentos energéticos e protéicos), que, em dias subseqüentes, foram transferidos aos cinco aquários de coleta de fezes a fim de se obterem cinco repetições por tratamento. 
Às 18h os tanques-rede eram transferidos para os aquários de digestibilidade, um para cada tanque-rede, com capacidade para $300 \mathrm{~L}$. Os aquários de digestibilidade apresentam seu terço inferior em formato cônico, o que possibilitava a coleta das fezes por gravidade. As gaiolas foram mantidas nos aquários de digestibilidade até a manhã do dia seguinte, quando foram devolvidas aos tanques de alimentação para um novo ciclo de coleta. Esse procedimento possibilitou a obtenção de fezes sem contaminação por sobras de ração ou acúmulo de nutrientes na água dos aquários de coleta. Toda a água utilizada nos aquários de digestibilidade foi substituída para evitar contaminação nas coletas seguintes.

As fezes coletadas foram congeladas a $-20^{\circ} \mathrm{C}$, armazenadas e posteriormente desidratadas a $55,0^{\circ} \mathrm{C}$ por 48 horas. Depois de secas, com o auxílio de uma lupa as amostras passaram por uma triagem para retirada de escamas, quando presentes, e em seguida foram moídas para as análises químicas. Os coeficientes de digestibilidade foram determinados pelo método indireto utilizando-se óxido de cromo III como indicador inerte $(0,10 \%)$, segundo metodologia proposta por Lovell (1989).

As análises para determinação da concentração de cromo nas fezes e nas rações foram realizadas a partir da mineralização ácida das amostras em forno de microondas e posterior quantificação do cromo por espectrometria de absorção atômica (Shimadzu Atomic Absorption spectrophotometers AA6800). A determinação do fósforo (P) total foi realizada pelo método de azul de molibdênio com utilização de Bi (II) como catalisador (AOAC, 1990).

Os coeficientes de digestibilidade aparente do fósforo da ração-referência e das rações-testes foram calculados com base na fórmula (Nose, 1960):

$$
C D A(\%)=100-\left[100\left(\frac{\% C r_{2} O_{3 r}}{\% C r_{2} O_{f}}\right) \cdot\left(\frac{\% N_{f}}{\% N_{r}}\right)\right]
$$

em que CDA é o coeficiente de digestibilidade aparente (\%); $\% \mathrm{Cr}_{2} \mathrm{O}_{3 \mathrm{r}}$, a porcentagem de óxido de cromo na ração; $\% \mathrm{Cr}_{2} \mathrm{O}_{3 \mathrm{f}}$, a porcentagem de óxido de cromo nas fezes; $\% \mathrm{~N}_{\mathrm{f}}$, a porcentagem de proteína ou aminoácidos nas fezes; $\% \mathrm{~N}_{\mathrm{r}}$, a porcentagem de proteína ou aminoácido na ração.

A disponibilidade aparente de fósforo dos alimentos avaliados, assim como as respectivas suplementações de fitase, foi calculada de acordo com Foster (1999):

$$
C D A_{N}=\frac{[(a+b) \times C D A d c-(a) \times C D A d r]}{b}
$$

em que: CDAn é o coeficiente de digestibilidade aparente do nutriente; CDAdc, o coeficiente de digestibilidade aparente da dieta combinada; CDAdr, o coeficiente de digestibilidade aparente da ração-referência; $a$, a contribuição do nutriente ou energia da ração-referência para o conteúdo do nutriente ou energia da ração combinada; $b$, a contribuição do nutriente ou energia pelo ingrediente teste para o conteúdo do nutriente da ração-referência; $a+b$, o nutriente ou a energia total na ração-teste.

Os parâmetros de oxigênio dissolvido (mg/L) e pH foram determinados semanalmente e a temperatura da água monitorada diariamente. A temperatura foi mantida estável por meio de aquecedores ligados a termostato digital.

Para análise estatística, utilizou-se o programa computacional Statistical Analysis System (SAS, 1995). Os resultados dos estudos foram avaliados por meio da técnica da análise de variância e quando significativo, aplicou-se o teste Tukey a 5,00\% de significância.

\section{Resultados e Discussão}

Os valores médios obtidos para temperatura, oxigênio dissolvido e $\mathrm{pH}$ da água dos aquários experimentais foram $26,00 \pm 1,00^{\circ} \mathrm{C}, 7,20 \pm 1,00 \mathrm{mg} / \mathrm{L} \mathrm{e} \mathrm{7,5} \pm 0,60$, respectivamente, e mantiveram-se na faixa recomendada por Popma \& Green (1990) para tilápias.

Entre os alimentos da ração-referência (sem a suplementação da enzima fitase), os maiores valores de disponibilidade aparente para o fósforo foram obtidos nos alimentos protéicos (Tabela 3). Com exceção do farelo de algodão, que apresentou CDA de 52,88\%, todos os demais permaneceram com seus CDA relativamente próximos, variando de 22,17\% (glúten de milho) a 26,42\% (farelo de girassol). O coeficiente de digestibilidade do fósforo da soja extrusada $(26,27 \%)$ foi $4,0 \%$ superior ao obtido no farelo de soja (22,31\%).

Valores superiores aos obtidos nesse estudo para o CDA do fósforo do farelo de soja foram obtidos por Miranda et al. (2000) e Furuya et al. (2004), que, em pesquisa com tilápias-do-nilo, encontraram valores de 35,13 e 47,76\%, respectivamente, e por Lovell (1978) e Robinson (1996), os quais obtiveram para o bagre-do-canal disponibilidade aparente do fósforo de 52,00 e 49,00\%, respectivamente. Resultados próximos aos obtidos nesse estudo sem a suplementação de fitase e para outras espécies de peixes foram apresentados por Sugiura et al. (1998), de 22,00 e $28,40 \%$ para o coeficiente de disponibilidade aparente do fósforo no farelo de soja em pesquisa realizada com truta arco-íris (Oncorhynchus mykiss) e salmão (Salmo salar), respectivamente, e por Wilson et al. (1982) para o bagre-docanal (Ictalurus punctatus), 29,00\%. 
Tabela 3 - Disponibilidade aparente do fósforo $(P)$ de alimentos de origem vegetal suplementados ou não com fitase para tilápias-donilo (\% MS)

Table 3 - $\quad$ Apparent availability coefficient for phosphorus (P) from feeds of plant origin supplementated or not with phytase for Nile tilapia (\% DM)

\begin{tabular}{|c|c|c|c|}
\hline \multirow[t]{2}{*}{$\begin{array}{l}\text { Alimento } \\
\text { Feed }\end{array}$} & \multicolumn{3}{|c|}{$\begin{array}{l}\text { Disponibilidade (\%) } \\
\text { Availability }\end{array}$} \\
\hline & \multicolumn{3}{|c|}{$\begin{array}{l}\text { Nível de suplementação de fitase (uf/kg) } \\
\text { Level phytase supplementation ( } \mathrm{uf} / \mathrm{kg})\end{array}$} \\
\hline Energético (Energetic) & 0 & 1.000 & 2.000 \\
\hline $\begin{array}{l}\text { Milho (Corn) } \\
\text { Milho extrusado (Extruded corn) } \\
\text { Farelo de trigo (Wheat meal) } \\
\text { Sorgo baixo tanino (Low-tannin sorghum) } \\
\text { Farelo de arroz (Rice meal) }\end{array}$ & $\begin{array}{l}11,44 \pm 1,49^{\mathrm{c}} \\
13,15 \pm 1,93^{\mathrm{c}} \\
53,11 \pm 4,07^{\mathrm{a}} \\
24,09 \pm 2,86^{\mathrm{c}} \\
17,29 \pm 2,48^{\mathrm{c}}\end{array}$ & $\begin{array}{l}24,73 \pm 3,88^{\mathrm{b}} \\
52,96 \pm 6,21^{\mathrm{b}} \\
53,39 \pm 2,42^{\mathrm{a}} \\
45,73 \pm 2,37^{\mathrm{b}} \\
52,41 \pm 4,98^{\mathrm{b}}\end{array}$ & $\begin{array}{l}37,19 \pm 5,38^{\mathrm{a}} \\
63,89 \pm 1,24^{\mathrm{a}} \\
51,20 \pm 2,10^{\mathrm{a}} \\
71,70 \pm 5,49^{\mathrm{a}} \\
63,26 \pm 6,66^{\mathrm{a}}\end{array}$ \\
\hline \multicolumn{4}{|l|}{ Protéico (Protein) } \\
\hline $\begin{array}{l}\text { Farelo de soja (Soybean meal) } \\
\text { F. de soja extrusado (Extruded soybean meal) } \\
\text { Glúten de milho (Corn gluten meal) } \\
\text { Farelo de algodão (Cottonseed meal) } \\
\text { Farelo de girassol (Sunflower meal) }\end{array}$ & $\begin{array}{l}22,31 \pm 2,02^{\mathrm{b}} \\
26,27 \pm 3,88^{\mathrm{b}} \\
22,17 \pm 1,85^{\mathrm{c}} \\
52,88 \pm 3,43^{\mathrm{a}} \\
26,42 \pm 3,37^{\mathrm{b}}\end{array}$ & $\begin{array}{l}27,70 \pm 3,89^{\mathrm{b}} \\
33,33 \pm 1,61^{\mathrm{a}} \\
44,44 \pm 0,77^{\mathrm{b}} \\
55,91 \pm 5,14^{\mathrm{a}} \\
33,93 \pm 1,51^{\mathrm{a}}\end{array}$ & $\begin{array}{l}48,13 \pm 5,40^{\mathrm{a}} \\
32,04 \pm 1,73^{\mathrm{a}} \\
65,27 \pm 5,62^{\mathrm{a}} \\
56,81 \pm 6,63^{\mathrm{a}} \\
33,41 \pm 3,32^{\mathrm{a}}\end{array}$ \\
\hline
\end{tabular}

Médias seguidas de letras iguais na linha diferem $(P<0,05)$ pelo teste Tukey (Means followed by equal letters within a row differ [P<0.05] by Tukey test).

Entre os alimentos protéicos estudados, o glúten de milho foi o que apresentou o menor CDA do fósforo (22,17\%). Entretanto, valor superior foi encontrado por Riche \& Brown (1996), que avaliaram a disponibilidade aparente de vários alimentos para a truta arco-íris e obtiveram CDA de $30,70 \%$ para o glúten de milho. Os resultados obtidos (Tabela 3) para os alimentos energéticos destacam-se principalmente pelos valores de CDA do farelo de trigo (53,11\%) e do sorgo baixo tanino (24,09\%). O coeficiente de digestibilidade encontrado para o farelo de trigo nesse estudo foi semelhante ao obtido por Sugiura et al. (1998) em pesquisa com truta arco-íris (55,30\%). Entretanto, foi superior aos valores encontrados por Furuya et al. (2004) e Miranda et al. (2000), em tilápias-do-nilo (29,49 e 31,49\%, respectivamente), Lovell (1978), em bagre-do-canal (28,00\%), e Sugiura et al. (1998), em salmão (41,90\%).

Os coeficientes de digestibilidade do fósforo (Tabela 3) calculados para o milho, o milho extrusado e o farelo de arroz foram inferiores aos obtidos para o farelo de trigo e o sorgo baixo tanino. Entretanto, o coeficiente de digestibilidade do fósforo no milho foi maior que o obtido por Miranda et al. (2000), em pesquisa com essa mesma espécie (11,44\%), e inferior aos encontrados por Furuya et al. (2004), em tilápiado-nilo (50,0\%), e Lovell (1978), em bagre-do-canal (25,00\%).

A baixa disponibilidade do fósforo obtida nos alimentos de origem vegetal se deve à forma como esse mineral está presente nesses alimentos. Nos vegetais, o fósforo faz parte de uma molécula bastante complexa denominada hexafosfato de inositol ou fitato e pode compor até $81,00 \%$ do conteúdo de fosfato presente nos vegetais (Riche \& Brown, 1996). De acordo com Kornegay (1999), o fitato está presente nas plantas de modo geral e contêm alta quantidade de fósforo (28,20\%); apresenta ainda grande capacidade de quelação com outros minerais, o que lhe confere a denominação de antinutriente (Liu, 1998).

O fósforo presente na molécula de fitato apresenta-se indisponível para a maioria dos animais monogástricos e para os peixes, em razão da ausência da enzima fitase endógena (Vielma et al., 1998), a qual disponibiliza o fósforo presente nessa molécula.

Os valores de disponibilidade aparente do fósforo obtidos nesse estudo confirmam as observações realizadas por vários autores para várias espécies de peixes, os quais destacaram a baixa disponibilidade do fósforo presente na forma de fitato (Andrews et al., 1973; Ketola, 1975; Ogino et al., 1979; Rodehutscord \& Pfeffer, 1995; Schãfer et al., 1995; Oliva-Teles et al., 1998; Vielma et al., 1998; Foster et al., 1999; Furuya et al., 2001).

Os coeficientes de digestibilidade do fósforo (Tabela 3) para os alimentos sem suplementação de fitase comprovam que, exceto no farelo de trigo e no farelo de algodão, há baixa disponibilidade desse mineral, cujos valores são menores que aqueles descritos na literatura para diversas espécies.

Entre os alimentos protéicos e energéticos, o CDA do farelo de trigo (53,11\%) e do farelo de algodão (52,88\%) não aumentaram $(\mathrm{P}>0,05)$ com a suplementação de 1.000 ou $2.000 \mathrm{uf} / \mathrm{kg}$.

A enzima fitase está amplamente distribuída e pode ser encontrada nas plantas, em tecido animal e microrganismos; nas plantas ocorre em cereais, legumes e vários tipos de sementes, o que pode melhorar a disponibilidade de seus 
nutrientes, principalmente minerais, em razão da presença natural desta enzima (Liu, 1998).

De acordo com Kornegay (1999), o grão de trigo se destaca pelos elevados níveis da enzima fitase (até 2.957 uf $/ \mathrm{kg}$ ), enquanto o farelo de trigo apresenta aproximadamente $1.193 \mathrm{uf} / \mathrm{kg}$, valores superiores aos descritos por esse autor para outros vegetais como o milho (15 uf/kg) e o sorgo (24 uf $/ \mathrm{kg}$ ). Esses resultados podem explicar os maiores valores de CDA para o fósforo no farelo de trigo e o efeito nulo da suplementação de fitase mesmo quando suplementada com $2.000 \mathrm{uf} / \mathrm{kg}$ para este alimento.

Os coeficientes de digestibiliade dos demais alimentos aumentou significativamente $(\mathrm{P}<0,05)$ com a suplementação da enzima fitase. Entre estes alimentos, apenas a soja extrusada e o farelo de girassol apresentaram máxima disponibilidade com a suplementação de $1.000 \mathrm{uf} / \mathrm{kg}$. Mesmo assim, os CDA desses alimentos não ultrapassaram 34,00\%.

Apesar de na literatura não haver relatos sobre a ação da suplementação da fitase especificamente para os alimentos, níveis de suplementação próximos ao utilizado nesse estudo (1.000 uf/kg) foram também avaliados em rações práticas para algumas espécies de peixes. Nessas pesquisas, foram encontradas boas respostas para a disponibilidade do fósforo. Lanari et al. (1998), em estudo com juvenis de truta arco-íris, obtiveram melhores CDA (aumento de 56,80 para $68,10 \%$ ) para o fósforo com a suplementação de $1.000 \mathrm{uf} / \mathrm{kg}$ em rações à base de farinha de sangue e farelo de soja. Esse mesmo nível de suplementação de fitase foi utilizado por Rodehutscord \& Pfeffer (1995) em rações à base de farelo de soja, também para a truta arco-íris. Esses autores observaram aumento de $25,00 \%$ para $57,00 \%$ no CDA do fósforo. Oliva-Teles et al. (1998), em pesquisa com o seabass (Dicentrarchus labrax), utilizaram rações compostas de farelo de soja e farelo de trigo suplementadas com $1.000 \mathrm{uf} / \mathrm{kg}$ e obtiveram aumento de 25,20 para $79,80 \%$ no coeficiente de digestibilidade do fósforo.

Níveis de suplementação inferiores ao desse estudo foram avaliados por vários pesquisadores e promoveram boas respostas no CDA do fósforo. Robinson et al. (1996) constataram redução de 33,00\% na excreção de fósforo com a suplementação de apenas 500 uf/kg em rações para o bagre-do-canal. Melhores respostas para o coeficiente de digestibilidade do fósforo também foram obtidas em juvenis de salmão-do-atlântico com esse mesmo nível de suplementação em pesquisa realizada por Storebakken et al. (1998), os quais encontraram aumento de 29,70 para 48,80\% no CDA do fósforo.

Nível de suplementação de fitase superior foi estimado por Furuya et al. (2001), que avaliaram em tilápia-do-nilo a ação dessa enzima na disponibilidade aparente do fósforo em rações à base de alimentos vegetais. Esses autores encontraram melhores CDA com a suplementação de até 688 uf $/ \mathrm{kg}$, valor próximo ao proposto por Hughes \& Soares (1998), 800 uf/kg, os quais observaram aumento de 29,70 para $82,80 \%$ em estudo com o striped bass (Morone saxatilis).

Neste estudo, a suplementação com 2.000 uf/kg proporcionou melhores respostas de CDA do fósforo para o milho (37,19\%), o milho extrusado (63,89\%), o sorgo baixo tanino (71,70\%), o farelo de arroz (63,26\%), o farelo de soja (48,13\%) e o glúten de milho (65,27\%). Resultados semelhantes ao desse estudo foram obtidos por Riche \& Brown (1996) em truta arco-íris. Esses autores obtiveram CDA do fósforo de $46,6 \%$ para o farelo de soja e de $56,30 \%$ para o farelo de algodão quando suplementaram a dieta com $3.750 \mathrm{uf} / \mathrm{kg}$. Esses autores encontraram ainda valor de CDA superior para o glúten de milho (76,80\%) em comparação aos 65,27\% obtidos nesse estudo.

Nesta pesquisa, os melhores resultados de disponibilidade de fósforo encontrados a partir da suplementação com 2.000 uf/kg confirmam os obtidos com diferentes espécies de peixes apresentados na literatura e demonstram a eficiência desta enzima em disponibilizar o fósforo da molécula de fitato presente em alimentos de origem vegetal.

Em trabalho com ração à base de concentrado protéico de soja para juvenis de truta arco-íris, Vielma et al. (1998) obtiveram aumento de 44,50\% para $69,70 \%$ no CDA do fósforo com a suplementação de $1.500 \mathrm{uf} / \mathrm{kg}$. Entretanto, Foster et al. (1999), em pesquisa com essa mesma espécie, avaliaram a degradação do ácido fítico e a disponibilidade de minerais em rações à base de farelo de canola e obtiveram melhor disponibilidade do ácido fítico (4,80 para 45,40\%) e do fósforo (37,40 para 51,00\%) quando utilizaram níveis elevados de fitase (4.500 uf $/ \mathrm{kg})$.

A grande eficiência da fitase foi ainda relatada por Massumoto et al. (2001), os quais observaram aumento de 8,90 para 87,30\% no CDA do fósforo com a suplementação de $2.500 \mathrm{uf} / \mathrm{kg}$ em rações à base de farelo de soja para o flounder japonês (Paralichthys olivaceus).

Dos seis alimentos nos quais a suplementação com $2.000 \mathrm{uf} / \mathrm{kg}$ foi eficaz, a melhora na disponibilização de fósforo para o milho e para o farelo de soja justificam a suplementação de fitase em rações para peixes de clima tropical. Entretanto, os CDA de 11,44\% para 37,19\% (milho) e de 22,31 para $48,13 \%$ (farelo de soja) encontrados para esses dois alimentos ainda podem ser considerados aquém dos esperados, o que justifica a realização de outros estudos na tentativa de melhorar os níveis de disponibilidade desse mineral. 
Por outro lado, a significativa disponibilização proporcionada pela presença de $2.000 \mathrm{uf} / \mathrm{kg}$ no farelo de arroz, no milho extrusado, no glúten de milho e no sorgo baixo tanino destaca os objetivos deste trabalho, demonstrando a possibilidade de se aumentar a disponibilidade do fósforo em rações para peixes, o que permite formular rações mais equilibradas para essa espécie e com assegurada diminuição da excreção desse mineral no meio ambiente.

\section{Conclusões}

A disponibilidade do fósforo varia de acordo com o alimento vegetal. Em alimentos como a soja extrusada, o farelo de girassol, o milho, omilho extrusado, o sorgo baixo tanino, o farelo de arroz, o farelo de soja e o glúten de milho, a disponibilidade desse mineral pode ser melhorada com a utilização de fitase, entretanto, a suplementação dessa enzima não tem efeito sobre o farelo de trigo e o farelo de algodão.

\section{Agradecimento}

Aos alunos de Pós-Graduação Hamilton Hisano, Jeison E.C. Ferrari, Geisa K. Kleemman e Edson de Souza Freire e aos funcionários do Laboratório de Química do IB-Unesp e do Laboratório de Bromatologia da FMVZ-Unesp/ Botucatu.

\section{Literatura Citada}

AMERICAN INSTITUTE OF NUTRITION - AIN, Report of the american institute of nutrition ad hoc committee on standards for nutritional studies. Journal Nutrition, v.107, p.13401348, 1977.

ASSOCIATION OF OFFICIAL ANALYTICAL CHEMISTS AOAC. Official methods of analysis. 15.ed. Arlington: 1990. v.1, 684p.

ANDREWS, J.W.; DAVIS, J.M.; CAMPBELL. C. Effects of dietary calcium and phosphorus on growth, food conversion, bone ash and hematocrit levels of catfish. Journal Nutrition, v.103, p.766-771, 1973.

FORSTER, I.; HIGGS D.A; DOSANJH, B.S. Potential for dietary phytase to improve the nutritive value of canola protein concentrate and decrease phosphorus output in rainbow trout (Oncorhynchus mykiss) held in $11^{\circ} \mathrm{C}$ fresh water. Aquaculture, v.179, p.109-125, 1999.

FOSTER, I. A note on the method of calculating digestibility coefficients of nutrients provided by single ingredients to feeds of aquatic animals. Aquaculture Nutrition, v.5, p.143-145, 1999.

FOSTER, I., HIGGS, D.A.; DOSANJH, B.S. Potential for dietary phytase to improve the nutritive value of canola protein concentrate and decrease phosphorus output in rainbow trout (Oncorhynchus mykiss) held in $11^{\circ} \mathrm{C}$ fresh water. Aquaculture, v.179, p.109-125, 1999.

FURUYA, W.M.; PEZZATO, L.E.; BARROS, M.M. et al. Use of ideal protein concept for precision formulation of amino acids level in diets with and without dicalcium phosphate for juvenile Nile tilapia. Aquaculture Research, v.35, p.110-1116, 2004.
FURUYA, W.M.; GONÇALVES, G.S.; FURUYA, V.R.B. et al. Fitase na alimentação da Tilápia do Nilo (Oreochromis niloticus). Desempenho e digestibilidade. Revista Brasileira de Zootecnia, v.30 n.3, p.924-929, 2001.

GONÇALVES, G.S.; PEZZATO, L.E.; BARROS, M.M. et al. Disponibilidade aparente do $\mathrm{Mg}, \mathrm{Ca}, \mathrm{Zn}, \mathrm{Cu}, \mathrm{Mn}$ e $\mathrm{Fe}$ e suplementação de fitase em alimentos vegetais para a Tilápia do Nilo. Revista Brasileira de Zootecnia, v.34, n.6, p.21552163, 2005.

HUGHES, K.P.; SOARES JR., J.H. Efficacy of phytase on phosphorus utilization in practical diets fed to striped bass Morone saxatilis. Aquaculture Nutrition, v.4, p.133-140, 1998.

KETOLA, H.G. Requirements of Atlantic salmon for dietary phosphorus. Transactions of the American Fisheries Society, v.104, p.548-551, 1975.

KORNEGAY, E.T. Feeding to reduce nutrient excretion: effects of phytase on phosphorus and other nutrients. In: LYONS, T.P.; JACQUES, K.A. (Eds.) Biotechnology in the feed Industry, Nottingham: Nottingham University Press, 1999. p.461-489.

LANARI, D.; AGARO, E.D.; TURRI, C. Use of nonlinear regression to evaluate the effects of phytase enzyme treatment of plant protein diets for rainbow trout (Oncorhynchus mykiss). Aquaculture, v.161, p.345-356, 1998.

LEE, D.Y.; SCHROEDER, J.; GORDON, P.T. Enhancement of $\mathrm{Cu}$ bioavailability in the rat by phytic acid. Journal Nutrition, v.118, p.712, 1988.

LIU, B-L.; RAFIQ A.; TZENG Y-M. et al. The induction and characterization of phytase and beyond. Enzime and Microbial Technology, v.22, p.415-424, 1998.

LOVELL, R.T. Dietary phosphorus requirements of channel catfish (Ictalurus punctatus). Transactions of the American Fisheries Society, v.107, p.617-621, 1978.

LOVELL, T. Nutrition and feeding of fish. Auburn: Auburn University, 1988. 260p.

MIRANDA, E.C.; PEZZATO, A.C.; PEZZATO, L.E. et al. Disponibilidade aparente do fósforo em ingredientes pela tilápia do Nilo (Oreochromis niloticus). Acta Scientiarum, v.22, n.3, p.669-675, 2000.

NATIONAL RESEARCH COUNCIL - NRC. Nutrient requirements of warmwater fishes an shellfishes. Washington, D.C: National Academy Press, 1993. 102p.

NOLAN, K.B.; DUFAFIN. P.A. Effects of phytase on mineral bioavailability, in vitro studies on $\mathrm{Mg} 2+, \mathrm{Ca} 2+, \mathrm{Fe} 2+, \mathrm{Cu} 2+$ and $\mathrm{Zn2}+$ (also Cd2+) solubility in the presence of phytase. Journal Science Food Agriculture, v.40, p.79-85, 1987.

NOSE, T. On the digestion of food protein by gold-fish (Carassius auratus) L. and rainbow trout (Salmo irideus G.). Bulletin Freshwater Fish Research, v.10, p.11-22, 1960.

OGINO, C.B.; TAKEUCHI, L.; TAKEDA, H. et al. Availability of dietary phosphorus in carp and rainbow trout. Bulletin Japanese Science Fisheries, v.45, p.1527-1579, 1979.

OLIVA-TELES, A.; PEREIRA J.P.; GOUVEIA A. et al. Utilization of diets supplemented with microbial phytase by seabass (Dicentrarchus labrax) juveniles. Aquatic Living Resource, v.11, n.4, p.255-259, 1998.

RICHE, M.; BROWN, P.B. Availability of phosphorus from feedstuffs fed to rainbow trout (Oncorhynchus mykiss). Aquaculture, v.142, p.269-282, 1996.

ROBINSON, E.H.; JACKSON S.; LI, M.H. Supplemental phytase in catfish diets. Aquaculture Magazine, v.1, p.80-82, 1996.

RODEHUTSCORD, M.; PFEFFER, E. Effects of supplemental microbial phytase on phosphorus digetibility and utilization in rainbow trout (Oncorhynchus mykiss). Water Sciene Technology, v.31, n.10, p.143-147, 1995.

STATISTICAL ANALYSIS SYSTEMS - SAS. User's guide. version 6. 4.ed. Cary: 1995. 365p.

SCHÄFER, A.; KOPPE, W.M.; MEYER-BURGDORFF, H.G. et al. Effects of microbial phytase on utilization of native phosphorus carp in a diet based on soybean meal. Water Science Technology, v.31, n.10, p.140-155, 1995. 
STOREBAKKEN, T.; SHEARER, K.D.; ROEN, A.J. Availability of protein, phosphorus and other elements in fish meal, soyprotein concentrate and phytase-treated oy-proteinconcentrate-based diets to Atlantic salmon, Salmo salar. Aquaculture, v.161, p.365-379, 1998.

SUGIURA, S.H.; DONG F.M.; RATHBONE, C.K. et al. Apparent protein digestibility and mineral availabilities in various feeds ingredients for salmonid feds. Aquaculture, v.159, p.177202, 1998.

VIELMA, J.; LALL, S.P.; KOSKELA, J. et al. Effects of dietary phytase and cholecalciferol on phosphorus bioavailability in rainbow trout (Oncorhynchus mykiss). Aquaculture, v.63, n.3/ 4, p.309-323, 1998.
WATANABE, T.; TAKEUCHI, T.; MURAKAMI, A. et al. The availability to tilapia nilotica of phosphorus in white fish meal. Bulletin Japanese Society Science Fish, v.46, p.897-899, 1980.

WILSON, R.R.; ROBINSON, E.H.; GATLIN III, D.M. et al. Dietary requirement of channel catfish. Journal Nutrition, v.112, p.1197-1202, 1982. 